\title{
Habitat Selection and Nest Success of the Upland Sandpiper (Bartramia longicauda) in Ivvavik National Park, Yukon, Canada
}

\author{
Valerie Miller ${ }^{1}$, Erica Nol ${ }^{1,3}$, Linh P. NGUYeN $^{2}$, and Devin M. Turner ${ }^{1}$ \\ ${ }^{1}$ Department of Biology, Trent University, Peterborough, Ontario K9J 7B8 Canada \\ ${ }^{2}$ Parks Canada Agency, PO Box 1840, Inuvik, Northwest Territories X0E 0T0 Canada \\ ${ }^{3}$ Corresponding author: enol@trentu.ca
}

Miller, Valerie, Erica Nol, Linh P. Nguyen, and Devin M. Turner. 2014. Habitat selection and nest success of the Upland Sandpiper (Bartramia longicauda) in Ivvavik National Park, Yukon, Canada. Canadian Field-Naturalist 128(4): 341-349.

The Upland Sandpiper (Bartramia longicauda) is a grassland shorebird species associated primarily with prairie habitats in central North America. A disjunct and poorly studied population also occurs in Yukon, Canada, and Alaska, United States. We studied habitat selection of nesting Upland Sandpipers in Ivvavik National Park, Yukon, at the scales of microhabitat (1-m radius around nest) and putative home range (11.3-m radius plots at nests and within $50 \mathrm{~m}$ of nest). At the microhabitat scale, the Upland Sandpiper selected nest sites with lower visibility from above than that of their home range (median $91.5 \%$, range $70-98 \%$ versus median $99.0 \%$, range $85-100 \%$ ) and less-variable composition of vegetation than at random sites within the home range. Vegetation adjacent to the nest in the eastern quadrat was significantly shorter (mean \pm standard error: $10.6 \pm 1.55 \mathrm{~cm}$ ) than that in other directions around the nest $(>13 \mathrm{~cm})$; nest sites and microsites within home ranges were more often hummocky than random sites in the park. At the mesohabitat scale, Upland Sandpipers selected sites within home ranges with fewer trees than random sites within the park $(10.3 \pm 3.0$ trees per 11.3 -m-radius plot around nest versus $32.9 \pm 5.9$ trees per 11.3 -m-radius plot in the park) and greater herbaceous cover $(70.7 \% \pm 3.0 \%$ versus $56.2 \% \pm 3.7 \%)$. Despite the disproportionate use of sites with fewer trees, more herbaceous cover, and lower vertical visibility, these factors did not relate to nest success in our sample. Of the 24 nests found in 2010 and 2011, 22 contained four eggs and 2 contained three eggs. Upland Sandpipers at this high latitude site had a nesting success rate of $0.85 \pm 0.01$ and $0.56 \pm 0.01$ in 2010 and 2011, respectively, for a 21-day incubation period. Further assessment of the selected characteristics of nesting sites will improve our ability to predict the effects of northward shrub and tree encroachment on this grassland species.

Key Words: Upland Sandpiper; Bartramia longicauda; mesohabitat; microhabitat; nest-site selection; northern limit; shorebirds; Yukon; Ivvavik National Park

\section{Introduction}

Habitat selection refers to the preference of specific environmental attributes that differ from other sites to enhance fitness, survival, or both (Block and Brennan 1993; Jones 2001). Nest-site selection is a top-down, hierarchical process that begins at the regional scale followed by home range then specific nest site (Block and Brennan 1993; Jones 2001). Vegetation characteristics are typically important features of nest-site selection for birds (Rodrigues 1994; Bollinger 1995; Clark and Shutler 1999).

We studied vegetation characteristics that may influence nest-site selection by the Upland Sandpiper (Bartramia longicauda), a medium-sized, grassland-nesting shorebird. The largest part of the geographic range of the Upland Sandpiper is in the Great Plains of North America, although several small, disjunct populations occur in northwestern Canada and Alaska (Houston et al. 2011). In the central and southern part of its breeding range, the Upland Sandpiper prefers to nest in large open grasslands with flowering herbaceous vegetation and avoids woody and tall, dense vegetation (Kirsch and Higgins 1976; Ailes 1980; Bowen and Kruse 1993; Vickery et al. 1994; Dechant et al. 2003*). Despite some early publications on this species (Buss 1951; Campbell 1967), there has been a near absence of recent research from the northern disjunct range (Nouvet et al. 2008), where warmer temperatures, earlier springs, and longer growing seasons associated with climate change have resulted in the advancement of the treeline (Szeicz and Macdonald 1995; Sturm et al. 2001; Moen et al. 2004).

The objectives of our study were to describe the characteristics of the habitat surrounding nest sites at the microhabitat scale and within a 50-m radius, the presumed home range of the Upland Sandpiper (Mong 2005) and to compare habitat characteristics of successful and unsuccessful nests at appropriate scales. Based on nesting habitat characteristics described for southern populations (Kirsch and Higgins 1976; Ailes 1980; Bowen and Kruse 1993; Bollinger 1995; Dechant et al. 2003*; Vickery et al. 2010*), we predicted that the Upland Sandpiper would select home ranges and nest sites in open, grassland areas with little woody cover. We also predicted that parents with nests closer to trees, more trees in the home range, and less vertical nest cover would experience less reproductive success than those with nests farther from trees, fewer trees in the home range, and more vertical nest cover. Our final objective was to document nest survival of the Upland Sandpiper in the disjunct northern population for com- 
parison with other studies from the centre of its breeding range.

\section{Study Area}

We collected data within a $4-\mathrm{km}^{2}$ area surrounding Sheep Creek $\left(69^{\circ} 09^{\prime} \mathrm{N}, 140^{\circ} 09^{\prime} \mathrm{W}\right)$ in Ivvavik National Park, Yukon, Canada. Sheep Creek is located within the British Mountains, which run perpendicular to the Firth River (Brooks and Lane 2011*). Vegetation in this area was primarily a function of elevation. At low elevations, it was dominated by sedges (Carex spp.) and stunted White Spruce (Picea glauca [Moench] Voss). Dense stands of White Spruce occurred on steep, mostly south-facing slopes. Low-growing vegetation, e.g., Eight-petalled Mountain Avens (Dryas octopetala [L.]) and Entire-leaved Mountain Avens (D. integrifolia Vahl) and lichens and scattered shrubs, such as willows (Salix spp.), Glandular Birch (Betula glandulosa Michaux), and alder (Alnus spp.) occurred at high elevations. Potential predators of nests and sandpipers in the study area included Gray Jay (Perisoreus canadensis), Common Raven (Corvus corax), Merlin (Falco columbarius), Northern Shrike (Lanius excubitor), and Arctic Ground Squirrel (Citellus parryi).

\section{Methods}

Nest location

In 2010, we searched for nests from 3 to 28 June. Nests were found opportunistically, while searching for songbird nests for a concurrent study (Turner 2013). Nests were monitored every 2-7 days until 2 July when the final egg hatched. Nests were checked, if there were no predators detected in the area, by flushing the adult bird from the nest. In 2011, the Upland Sandpiper was a focal species for our study. We searched for nests from 1 to 25 June in three ways: incidentally, while walking through potential home ranges; by dragging a 5-m rope, weighted down with tin cans, between two researchers; or with two or more researchers walking 2-3 m apart. Although we concentrated search efforts in open areas, we also searched areas typically not used as nesting sites by Upland Sandpipers, such as stands of stunted White Spruce on the flat, shallow slopes, and heavily forested areas. At discovery, we chose one egg from each nest and used the float stages described by Liebezeit et al. (2007), assuming a 21-day incubation period, to estimate hatch date (Houston et al. 2011). We monitored nests every 3-4 days during incubation and every 2 days after the estimated hatch date until eggs showed signs of hatching (starring or pipping), after which we checked nests daily until hatch. The last egg hatched on 10 July 2011. In both years, nest locations were recorded using a Garmin GPSMAP 60CSx global positioning system unit (Garmin International Inc., Olathe, Kansas, USA) and marked with naturally occurring objects placed within $10 \mathrm{~m}$ of nests to facilitate monitoring.

\section{Nest success}

We considered a nest to be successful if one or more eggs was alive or had hatched (judged by observation of adults with chicks or clean eggshell remnants in the nest) by the last visit. We considered nests abandoned when no adults were present in the area, or eggs were cold on three successive visits. We examined nests with missing eggs for evidence of predation (tracks or broken eggshells). We estimated daily survival of nests using the Mayfield estimate, assuming the nest was lost at the midpoint between the last visit when it was active and the first visit showing it had failed (Mayfield 1975; Johnson 1979). We compared tree density, distance to nearest tree, and vertical cover of successful and failed nests using two sample $t$-tests. We used the delta method (Powell 2007) for calculating the variance in period survival rate. We did not use logistic exposure methods or other models for our analysis of nest survival or habitat preferences because of the small number of nests in our sample. For all analyses, we set $\alpha$ at 0.05 .

\section{Habitat analysis}

Most vegetation variables were assessed differently in 2010 and 2011 because of logistical constraints, but assessments were made within two weeks of hatching or nest failure in both years. In 2010, we measured vegetation characteristics at 10 nests and 10 random points in the park. In 2011, we also measured vegetation characteristics in 16 sampling plots within 50-m radius of the nest ("home range"), as well as 16 "nest" and 23 "park" sites. We did not document space use or movement, but selected a 50-m radius to include the presumed home range (Houston et al. 2011). Although Upland Sandpipers are known to breed in loose colonies and exhibit little territoriality, other populations have nests more than $300 \mathrm{~m}$ apart (Casey et al. 2011, Houston et al. 2011). To select sampling sites within the presumed home range, a random direction and distance up to $50 \mathrm{~m}$ from the nest were selected, excluding sites in water. To select park sites, we randomly chose coordinates in the study area using ArcGIS (ESRI, Redlands, California, USA) and located sites in the field using a GPS unit. Randomly chosen sites were excluded if they were in water, had a high tree density ( $>80$ trees with a diameter at breast height $>2.5 \mathrm{~cm}$ in an $11.3-\mathrm{m}$ radius), or were more than $150 \mathrm{~m}$ above the treeline in dry, sparsely vegetated areas. No nests were found in these environments in either year.

In both years, we measured variables at two scales: microhabitat (1-m-radius plots) and mesohabitat (11.3m-radius plots). In 2010, we measured height of the tallest vegetation in each cardinal direction within $5 \mathrm{~cm}$ of the point (using a ruler) and the elevation of the point (using a GPS unit and comparing with topographic maps for accuracy) at the microhabitat scale. We also visually estimated the proportion of the nest visible from $1 \mathrm{~m}$ above and the percentage cover of each species and other elements (water and bare ground) in the 
microhabitat. Rare and short $(<1 \mathrm{~cm})$ herbaceous species were ignored. At the mesohabitat scale, we paced the distance to the nearest tree (even if it was beyond the plot boundaries) or shrub greater than $1 \mathrm{~m}$ in height and recorded the plant species. The number of trees and shrubs over $1 \mathrm{~m}$ tall within the $11.3-\mathrm{m}$ radius plot was recorded, as well as the percentage cover of shrubs less than $1 \mathrm{~m}$ tall. The area of the habitat patch containing a nest or park site that did not contain trees was delineated by walking the inner perimeter of the surrounding trees using the track function on the GPS unit.

In 2011 at the microhabitat scale, we measured vegetation height near the nest cup and the elevation as in 2010. In addition, we visually estimated percentage vegetation cover, identifying each species (including dead sedges and grass), bare ground, water, litter, and lichens. The slope within the microhabitat was categorized as $\leq 5^{\circ}$ or $>5^{\circ}$. Visibility from above was estimated by placing a 13 -cm-diameter disc (the approximate diameter of most nests in our study) in the nest cup or at the centre of the home range or park microhabitat sites and estimating the proportion that was visible. The disc was brown and speckled black to resemble egg colouration. We recorded whether the site was on a hummock or flat ground. We also recorded the height of the tallest vegetation within the microhabitat radius (to the nearest $\mathrm{mm}$ ), the species, whether it was dead or alive, and its direction and distance from the nest.

At the mesohabitat scale, we recorded the number and species of living and dead trees over $1 \mathrm{~m}$ tall, the number and species of shrubs over or equal to $1 \mathrm{~m}$ tall, and the percentage cover of shrubs less than $1 \mathrm{~m}$. Trees less than $30 \mathrm{~cm}$ in height with a single stem were designated as seedlings and counted. The distance to the nearest tree or shrub over $1 \mathrm{~m}$ (even if outside the plot boundaries) in each cardinal direction (using an estimated $10^{\circ}$ swath) was paced and the species was recorded, as well as the overall nearest tree and its direction. Percentage cover of the herbaceous layer, rock and bare ground, lichens, and water were visually estimated. Slope within the mesohabitat was visually estimated in the same categories as above.

\section{Statistical analysis}

All data were tested for normality and homogeneity of variances using Statistica v. 7.0 (StatSoft Inc., Tulsa, Oklahoma, USA). Data were transformed to meet the assumptions of parametric testing if necessary. If assumptions of normality were not met after transformation, we used non-parametric tests. We used ANOVA to determine whether vegetation height around the nest varied as a function of direction. We then calculated the average vegetation height adjacent to the nest for further analyses. Data for nest and park plots from 2010 at both microhabitat and mesohabitat scales were compared using $t$-tests.
Data for nest, home range, and park plots from 2011 at both microhabitat and mesohabitat scales were compared using ANOVA (for continuous data); equality of medians was compared using $\chi^{2}$ and Kruskal-Wallis tests (for nonparametric data) and $\chi^{2}$ tests (for categorical data). Variables that were significantly correlated were removed from analysis. For example, height of tallest vegetation adjacent to the nest was correlated with the tallest vegetation within the microhabitat; thus, only the latter was retained for analysis. Before analysis, at the mesohabitat scale, we combined variables related to the number and percentage cover of shrubs and trees (e.g., numbers of trees over and under $1 \mathrm{~m}$ were combined). As results were similar for the combined and individual variables, we report results for combined variables only.

To assess differences in the composition of herbaceous plants at the microhabitat scale in both years, we used PERMANOVA, a permutational distributionfree method for assessing similarities in communities (Anderson 2005) and non-metric multidimensional scaling (MDS) plots with fourth-root transformed data using the Bray-Curtis similarity index. As vegetation cover was assessed differently in 2010 and 2011, this analysis was conducted separately by year. We excluded plant species that were present at fewer than three sites, as rare species have little effect on the BrayCurtis distance, but increase stress. Stress represents distortion in MDS plots; a value under 0.2 is considered a good visualization of the data (Clarke and Warwick 2001; Clarke and Gorley 2006). We also combined similar species, such as Louseworts (Pedicularis spp.), to reduce the number of variables. We identified 15 species in 2010 and 39 species or genera in 2011. PERMANOVA requires a balanced design, so we randomly selected 16 of the park sites for comparison in 2011.

We first assessed the similarity of the dispersion between the nest, home range, and park sites using PERMDISP (Anderson 2005). Despite a significant difference in the dispersion between the groups for both 2010 and 2011 (see Results), we elected to complete the PERMANOVA analysis to explore the data. For both PERMDISP and PERMANOVA, we used 4999 permutations.

To represent relations among nest, park, and home range sites graphically, we used PRIMER v. 6.13 (PRIMER-E Ltd., Plymouth, UK) to create MDS plots. The axes of these plots do not relate to the original variables, but the proximity of points within the plots gives a relative measure of similarity (e.g., closer points are more similar, Proctor et al. 2012). A hierarchical cluster analysis using group averages created a cluster overlay on the plot. Resemblance levels of 20, 40, 60, and $80 \%$ were used with a slackness value of $75 \%$.

We used $t$-tests to compare successful and failed nests (combining years to increase power) in terms of three habitat characteristics (vertical visibility, distance 
to the nearest tree and number of trees in the mesohabitat).

\section{Results}

\section{Microhabitat}

Vegetation height adjacent to nests varied as a function of direction, with vegetation significantly lower east of the nests than in other directions $\left(F_{3,73}=3.13\right.$, $P=0.03)$; mean height of vegetation ( \pm standard error): north, $13.2 \pm 1.5 \mathrm{~cm}$; east, $10.6 \pm 1.6 \mathrm{~cm}$; south, $13.4 \pm$ $1.2 \mathrm{~cm}$; west, $15.4 \pm 1.5 \mathrm{~cm}$. In 2010 , neither average tallest vegetation adjacent to nests nor vertical visibility differed between nest and park sites (Table 1). Using PERMANOVA, we found a marginally significant difference in vegetation composition between nest and park sites $\left(F_{1,19}=2.05, P=0.08\right)$, and a significant difference in average within-group dissimilarities $\left(F_{1,19}=\right.$ $8.64, P=0.01)$. Vegetation cover around nest sites had greater similarity $(61.6 \%)$ than at park sites $(45.7 \%)$. Based on the MDS plot, stress was 0.16 and similarities between the majority of the points were over $40 \%$.

Among the nests found in 2011, vertical visibility differed significantly between site types, with nest sites less visible than home range or park sites (Table 2). No other continuous microhabitat variables differed significantly between the three site types. Over half of all nests were on a gradual slope, but this proportion was not significantly different than that of home range and random park sites (Table 2). Nests were, on average, at an elevation of $254 \mathrm{~m}$ (similar to the value from 2010 , Table 1), a value that also did not differ significantly from home range or random sites (Table 2). Nest and home range sites were significantly more likely to be in hummocky habitats $(>80 \%)$ than random park sites $(47.8 \%)$.

In 2011, as in 2010, we found no significant differences in composition of the plant communities at nest, home range and park sites (PERMANOVA, $N=48$, $\left.F_{2,47}=1.25, P=0.24\right)$. The MDS plot shows that similarity of plant composition between points is over $40 \%$ and nest sites are concentrated toward the upper centre of the MDS plot (Figure 1). There were significant differences in within-group vegetation composition for all three site types (PERMDISP, $F_{2,47}=6.45, P=0.002$ ), with nest sites more similar than both park and home range sites, which were not different (Table 3).

\section{Mesohabitat}

Upland Sandpipers nested in Arctic and alpine tundra and wet sedge meadows, although they were restricted to drier locations in the latter. Nests occurred in both small and large clearings within the scattered stunted White Spruce. Most random park sites and nearly all home range locations were on gradual slopes, reflecting the hilly nature of the study area. Water in the park, home range and nest mesohabitat plots was relatively rare $(\leq 25 \%$; Table 2$)$. The openings used for nesting were small $(<0.1 \mathrm{ha})$, but these did not vary significantly in size from openings in the random park sites (Table 1).

Vegetation characteristics at this scale were similar between nest and park sites in 2010 (Table 1). In 2011, park sites had significantly more trees and less herbaceous cover than either home range or nest sites, which did not differ from each other (Figure 2, Table 2). None of the remaining variables differed across site types.

We found no significant differences between successful and unsuccessful nests in vertical visibility $\left(t_{23}=1.18, P=0.25\right)$, distance to the nearest tree $\left(t_{23}=\right.$ $0.63, P=0.53)$, or number of trees in the mesohabitat $\left(t_{23}=-0.92, P=0.37\right)$. Inter-nest distances were $288 \pm$ $45 \mathrm{~m}$ in 2010 and $234 \pm 42 \mathrm{~m}$ in 2011.

\section{Nest survival}

In 2010, we found 10 nests, eight with four eggs, one with three eggs and one with two chicks. In 2011, we found 16 nests, 14 with four eggs, one with three eggs and one after the chicks had hatched and left the nest. In 2010, eight nests hatched successfully, one nest contained whole broken shells on the last visit, and one nest was abandoned, while in 2011, nine were successful,

TABLE 1. Comparison of habitat characteristics at micro and meso scales between Upland Sandpiper (Bartramia longicauda) nest sites and random "park" sites at Sheep Creek, Ivvavik National Park, 2010.

\begin{tabular}{|c|c|c|c|}
\hline \multirow[b]{2}{*}{ Habitat characteristic } & \multicolumn{2}{|c|}{ Mean $( \pm$ SE) or median (range) } & \multirow[b]{2}{*}{$P$} \\
\hline & Nest $(n=10)$ & Park $(n=10)$ & \\
\hline $\begin{array}{l}\text { Microhabitat } \\
\text { Elevation, } \mathrm{m}^{*} \\
\text { Height of adjacent vegetation, cm } \\
\text { Vertical visibility, \%* }\end{array}$ & $\begin{array}{l}249.5(239-293) \\
11.3 \pm 1.4 \\
91.5(60.0-97.0)\end{array}$ & $\begin{array}{l}\mathrm{n} / \mathrm{a} \\
10.7 \pm 1.7 \\
82.5(0.0-100.0)\end{array}$ & $\begin{array}{l}-\overline{83} \\
0.85\end{array}$ \\
\hline $\begin{array}{l}\text { Mesohabitat } \\
\text { Area of clearing, } \mathrm{m}^{2} \\
\text { Distance to nearest tree, } \mathrm{m} \\
\text { Shrub cover, \% } \\
\text { Number of trees over } 1 \mathrm{~m} \text { tall } \dagger\end{array}$ & $\begin{array}{l}492.8 \pm 261.3 \\
3.4 \pm 0.9 \\
14.5 \pm 2.8 \\
17.1 \pm 8.6\end{array}$ & $\begin{array}{l}474.6 \pm 405.1 \\
4.5 \pm 1.0 \\
12.4 \pm 2.5 \\
24.3 \pm 5.0\end{array}$ & $\begin{array}{l}0.97 \\
0.41 \\
0.59 \\
0.48\end{array}$ \\
\hline
\end{tabular}

Note: $\mathrm{n} / \mathrm{a}=$ not applicable, $\mathrm{SE}=$ standard error.

* Results are presented as median (range) as the data do not conform to assumptions of normality.

$\dagger \log _{10}$ transformation used for analysis; means presented as untransformed data. 
TABLE 2. Comparison of habitat characteristics at micro and meso scales among Upland Sandpiper (Bartramia longicauda) nests, random home range sites and random park sites at Sheep Creek, Ivvavik National Park, 2011.

\begin{tabular}{|c|c|c|c|c|}
\hline \multirow[b]{2}{*}{ Habitat characteristic } & \multicolumn{3}{|c|}{ Mean $( \pm \mathrm{SE})$, median (range), or proportion $(\%)$} & \multirow[b]{2}{*}{$P$} \\
\hline & Nest $(n=16)$ & $\begin{array}{l}\text { Home range } \\
\quad(n=16)\end{array}$ & Park $(n=23)$ & \\
\hline \multicolumn{5}{|l|}{ Microhabitat } \\
\hline Elevation, $\mathrm{m}^{*}$ & $254(240-356)$ & $260(247-450)$ & $254(238-359)$ & 0.30 \\
\hline Tallest vegetation, $\mathrm{cm} \dagger$ & $30.4 \pm 1.8$ & $44.6 \pm 6.3$ & $54.7 \pm 13.1$ & 0.11 \\
\hline Distance to tallest vegetation, $\mathrm{cm}$ & $62.7 \pm 7.6$ & $74.3 \pm 5.9$ & $79.2 \pm 5.3$ & 0.17 \\
\hline Vertical visibility, $\% *$ & $91.5(70.0-98.0)$ & $99.0(85.0-100.0)$ & $99.0(82.0-100.0)$ & $0.0004 t$ \\
\hline Proportion $(\%)$ on hummock & $14 / 16(87.5)$ & $13 / 16(81.3)$ & $11 / 23(47.8)$ & $0.01 \ddagger$ \\
\hline Proportion $(\%)$ on gradual slope & $11 / 16(68.8)$ & $7 / 16(43.8)$ & $11 / 23(47.8)$ & 0.30 \\
\hline \multicolumn{5}{|l|}{ Mesohabitat } \\
\hline Herbaceous cover, $\%$ & $70.7 \pm 3.0$ & $61.5 \pm 5.2$ & $56.2 \pm 3.7$ & $0.04 \dagger$ \\
\hline Lichen cover, $\% \S$ & $2.2 \pm 0.7$ & $1.6 \pm 0.6$ & $2.3 \pm 0.7$ & $0.62^{\circ}$ \\
\hline Bare ground, $\% \dagger$ & $2.5 \pm 0.56$ & $6.0 \pm 2.5$ & $5.1 \pm 1.6$ & 0.81 \\
\hline Shrub cover, $\%$ & $18.2 \pm 2.9$ & $23.7 \pm 4.8$ & $22.5 \pm 2.9$ & 0.55 \\
\hline Number of shrubs over $1 \mathrm{~m}^{*}$ & $0.0(0.0-2.0)$ & $0.0(0.0-35.0)$ & $0.0(0.0-18.0)$ & 0.20 \\
\hline Number of saplings* & $0.0(0.0-4.0)$ & $0.0(0.0-4.0)$ & $0.0(0.0-38.0)$ & 0.18 \\
\hline Proportion (\%) on gradual slope & $11 / 16(68.8)$ & $7 / 16(43.8)$ & $17 / 23(73.9)$ & 0.14 \\
\hline Proportion (\%) with water & $3 / 16(18.8)$ & $4 / 16(25.0)$ & $2 / 23(8.7)$ & 0.37 \\
\hline Number of trees $\S$ & $10.3 \pm 3.0$ & $9.4 \pm 3.3$ & $32.9 \pm 5.9$ & $0.004 t$ \\
\hline
\end{tabular}

Note: $\mathrm{SE}=$ standard error.

*Results are presented as median (range) as the data do not conform to assumptions of normality.

$\dagger$ Inverse transformation; means presented as untransformed data.

$\ddagger$ Significant differences between site types.

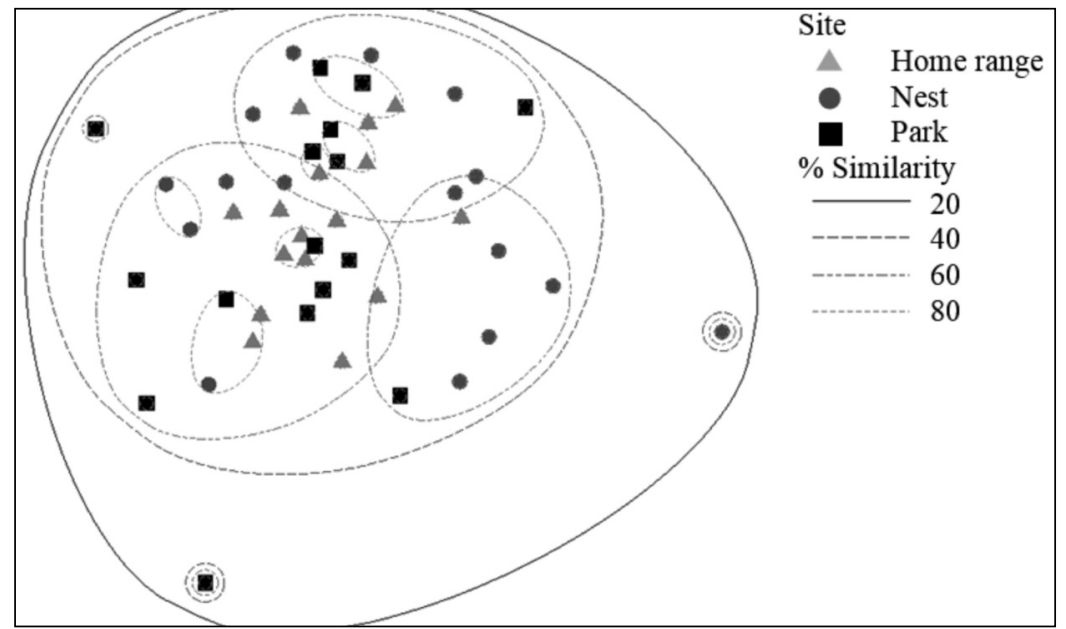

FIGURE 1. Non-metric multidimensional scaling plot of vegetation in the microhabitat at Upland Sandpiper (Bartramia longicauda) nests, random home range sites and random park sites at Sheep Creek, Ivvavik National Park, Yukon, Canada, 2011. Using the Bray-Curtis similarity index, the cluster overlay has resemblance levels of 20, 40, 60, and $80 \%$ and a slackness of $75 \%$. Close points indicate sites with more similar plant composition. Stress was 0.18 .

TABLE 3. Comparison of within-group similarity of vegetation at Upland Sandpiper (Bartramia longicauda) nests, random home range sites and random park sites at Sheep Creek, Ivvavik National Park, 2011, using PERMDISP.

\begin{tabular}{lclcc}
\hline \hline \multirow{2}{*}{ Site type } & Bray-Curtis index (average & & $t$ & $P$ \\
\hline Nest & within group similarity), $\%$ & Comparator & 2.7 & 0.009 \\
Home range & 66.3 & Home range & 4.0 & 0.001 \\
Park & 56.8 & Park & 0.7 & 0.520 \\
\hline \hline
\end{tabular}




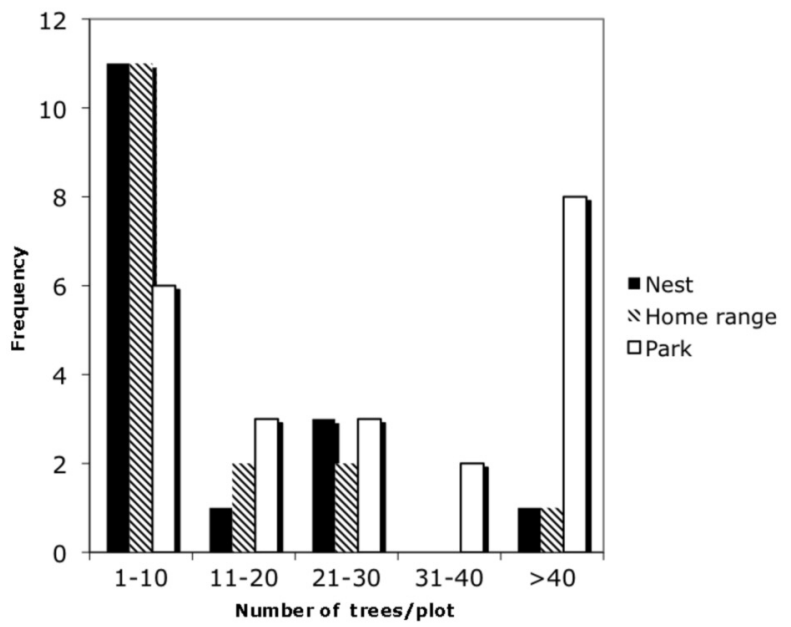

FIGURE 2. Frequency distribution of number of trees in the mesohabitat (11.3-m-radius plots) at Upland Sandpiper (Bartramia longicauda) nest and home range sites and random park sites at Sheep Creek, Ivvavik National Park, Yukon, Canada, 2011.

seven were unsuccessful, and the fate of two nests remained uncertain. Mayfield estimates of daily nest survival were $0.989 \pm 0.007(n=10)$ in 2010 and $0.976 \pm 0.010(n=14$, excluding the two uncertain nests) in 2011 for period survival rates of $0.851 \pm 0.135$ and $0.558 \pm 0.118$, respectively, assuming a 21-day incubation period.

\section{Discussion}

Of the many habitat variables we compared in this study, only a few affected the choice of nest site by Upland Sandpipers. As predicted, Upland Sandpipers nested in home ranges with fewer trees and greater herbaceous cover than found generally in this treeline region, although trees in the park were also relatively sparse (32.4 trees/ha). Upland Sandpipers placed their nests at sites with more vertical cover than available in their putative home ranges. The composition of low-lying species of Arctic plants within the nest sites was less variable than in the home range, suggesting that a site with a relatively homogeneous plant community is sought. Most nests were placed in areas dominated by sedges, with a mixture of Mountain Avens, Lapland Rosebay (Rhododendron lapponcium [L] Wahlenberg), mosses, and willows. None of the variables we studied predicted nest success of the Upland Sandpiper, although our sample size of nests was small.

Vegetation east of the nests was $2-5 \mathrm{~cm}$ shorter than in other directions. Upland Sandpipers probably entered the nest cup consistently from the east, facing into the predominant northwest wind, which would result in some trampling of vegetation. Orienting into the wind both reduces ruffling of the feathers (Gochfeld 1978) and gives incubating bird greater cover from wind, thus reducing conductive cooling.
Use of grasslands and other treeless habitats is a characteristic of the Upland Sandpiper in the southern and central part of its range (Kirsch and Higgins 1976; Ailes 1980; Bowen and Kruse 1993; Dechant et al. 2003*). In North Dakota, occupancy of mixed-prairie grassland by Upland Sandpipers is negatively correlated with the proportion of woodland. Therefore, Upland Sandpipers are designated a woodland sensitive species (Grant et al. 2004). Trees may provide perches for avian predators, as well as for their prey, increasing the potential for higher abundance and activity of predators associated with woody vegetation. Simultaneously, trees reduce visibility and diminish the ability of incubating adult Upland Sandpipers to sense these predators (Johnson and Temple 1990; Winter et al. 2000; Coppedge et al. 2001; Chapman et al. 2004; Grant et al. 2004; Graves et al. 2010). Although Upland Sandpipers avoided trees at the scale of their nests and home ranges in the Yukon, they did use trees in the landscape for perching and vocalizing while we were in the area of their nests. Shrub cover in northern Yukon may not have influenced Upland Sandpipers, as the majority of the shrubs in this habitat were short $(<20 \mathrm{~cm})$, not much taller than the herbaceous layer, and scattered in distribution. In addition, during the nesting season, the shrubs had limited to no foliage, thus reducing the effect on visibility.

Upland Sandpipers selected nesting sites with greater vertical cover or less visibility than random sites within the home range. Vertical or overhead cover, mostly by grasses and sedges in our study, can increase nest success by reducing visibility, especially for avian predators, and reduce egg loss from predation (Dwernychuk and Boag 1972; Martin 1993; DeLong et al. 1995; Stokes and Boersma 1998; Dion et al. 2000). The ben- 
eficial effect of overhead cover is especially important during incubation recesses when the movement of adults can make the nests more susceptible to avian predators (Smith et al. 2012). While incubating, Upland Sandpipers have a highly cryptic plumage, and the additional grasses and other plants that protruded around the nest cup probably decreased their conspicuousness even more. Overhead cover can also help to retain warmth around the nests (With and Webb 1993). As mean temperatures ranged from $-4.2^{\circ}$ to $26.9^{\circ} \mathrm{C}$ during incubation in Ivvavik National Park (Government of Canada 2014), features that reduce temperature stress on the incubating Upland Sandpipers may improve reproductive success.

Variation in plant species cover in the microhabitat around nests was lower than at random sites in the home range or park, although there was no significant difference in the amount of species cover. The reduced variation at nests suggests that Upland Sandpipers are avoiding sites at the extremes. For example, the maximum amount of bare ground at nesting sites was $9.0 \%$, whereas at home ranges, it was $91.0 \%$ and at park sites $28.5 \%$. Upland Sandpipers did not use sites that were wet, where Equisetum spp. were common, or dry, rocky sites, where Dryas spp. were common. Bare ground could occur at either dry sites where rocks and exposed ground were common or wet sites where the water had receded. In the future, vegetation should be categorized by habitat type (i.e., wet, dry, etc.) or structure, rather than by individual species, as it is unlikely that Upland Sandpipers can distinguish between plant species of similar height and shape.

Nest success (56-85\%) in this northern breeding population was at the high end of the range reported from other more southerly locations (see review in Garvey et al. 2013). This observation, albeit based on a small sample size, is consistent with predictions regarding a latitudinal effect on predation risk (McKinnon et al. 2010). Contrary to our predictions, nest success was not influenced by either distance to trees or number of trees at the mesohabitat scale, nor vertical cover. This may have been due to the small sample size of failed nests or because of a diverse predator community. When there is a diverse predator community that uses various cues and searching methods to find nests, it can result in no adaptive signal of habitat selection (Braden 1999, Dion et al. 2000). Further exploration of the relation between predator abundance and an encroaching treeline is needed in this northern location. In the prairies, Clay-colored (Spizella pallida) and Vesper Sparrows (Pooecetes gramineus) have greater nest survival near forest edges, as their main predator (the Thirteen-lined Ground Squirrel, Ictidomys tridecemlineatus) is primarily found in grassland interiors (Grant et al. 2006). By contrast, in predominantly forested areas, many species experience lower reproductive success near edges (Burke and Nol 2000). The nesting success of Upland Sandpipers in the Canadian prairies appears to be predominantly influenced by nest age and not by landscape features (Garvey et al. 2013), a result that is similar to our findings.

We have provided the first detailed description of the habitat of nesting Upland Sandpipers at the northern edge of their range. As in the prairie regions, Upland Sandpipers in the northern Yukon breed in home ranges with less tree cover and greater herbaceous cover than what is randomly found. Within Ivvavik National Park, Upland Sandpipers are restricted to inland, sparsely treed regions (Brown et al. 2007). In addition, within the park, Upland Sandpipers nest in flat valleys and along shallow slopes, as the mountains are too rocky for this grassland species and the steep, south-facing slopes have dense spruce cover. As early as the middle of the last century, Buss (1951) suggested the potential for habitat loss for Upland Sandpipers in the southern Yukon because of encroachment of vegetation into the clearings used for breeding. Given the already small openings $(<0.1 \mathrm{ha})$ in the sparsely forested landscape where Upland Sandpipers nest, habitat loss as a result of northward shrub and tree encroachment with climate warming is a real threat to this population's persistence.

\section{Acknowledgements}

We are extremely grateful for funding provided by Parks Canada, the Wildlife Management Advisory Council (North Slope), the Natural Sciences and Engineering Research Council and its Undergraduate Student Research Award program, and the Northern Scientific Training Program. We are especially grateful to Kayla Arey, whose plant identification expertise was invaluable. We thank the Parks Canada's Western Arctic Field Unit employees and volunteers for assistance with logistics and fieldwork. We also thank Brett Sandercock for detailed comments on an earlier version of this manuscript.

Documents Cited (marked * in text)

Brooks, G. R., and L. S. Lane. 2011. A guide to the landscape of the Firth River Valley, Ivvavik National Park. Parks Canada and Natural Resources Canada, Inuvik, Northwest Territories, Canada. Accessed 22 September 2014. http://parkscanadahistory.com/geology/firth-rivervalley.pdf.

Dechant, J. A., M. F. Dinkins, D. H. Johnson, L. D. Igl, C. M. Goldade, B. D. Parkin, and B. R. Euliss. 2003. Effects of management practices on grassland birds: Upland Sandpiper. Northern Prairie Wildlife Research Center, Jamestown, North Dakota, USA. Accessed 22 September 2014. http://www.npwrc.usgs.gov/resource/literatr/grasbird /upsa/upsa.htm.

Vickery, P. D., D. E. Blanco, and B. López-Lanús. 2010. Conservation plan for the Upland Sandpiper (Bartramia longicauda). Version 1.1. Manomet Center for Conservation Sciences, Manomet, Massachusetts, USA. Accessed 22 September 2014. http://www.whsrn.org/sites/default /files/file/Upland_Sandpiper_Conservation_Plan_v1.1 10_02-28.pdf. 


\section{Literature Cited}

Ailes, I. W. 1980. Breeding biology and habitat use of the Upland Sandpiper in central Wisconsin. Passenger Pigeon 42: 53-63.

Anderson, M. J. 2005. PERMDISP: a FORTRAN computer program for permutational analysis of multivariate dispersions (for any two-factor ANOVA design) using permutation tests. Department of Statistics, University of Auckland, Auckland, New Zealand.

Block, W. M., and L. A. Brennan. 1993. The habitat concept in ornithology: theory and applications. Pages 35-91 in Current Ornithology, Volume 11. Edited by D. M. Power. Plenum Press, New York, New York, USA.

Bollinger, E. K. 1995. Successional changes and habitat selection in hayfield bird communities. The Auk 112: 720-730.

Bowen, B. S., and A. D. Kruse. 1993. Effects of grazing on nesting by upland sandpipers in southcentral North Dakota. Journal of Wildlife Management 57: 291-301.

Braden, G. T. 1999. Does nest placement affect the fate or productivity of California Gnatcatcher nests? The Auk 116: 984-993.

Brown, S., J. Bart, R. B. Lanctot, J. A. Johnson, S. Kendall, D. Payer, and J. Johnson. 2007. Shorebird abundance and distribution on the coastal plain of the Arctic National Wildlife Refuge. The Condor 109: 1-14.

Burke, D. M., and E. Nol. 2000. Landscape and fragment size effects on reproductive success of forest-breeding birds in Ontario. Ecological Applications 10: 1749-1761.

Buss, I. O. 1951. The Upland Plover in southwestern Yukon Territory. Arctic 4: 204-213.

Campbell, J. M. 1967. The Upland Plover in arctic Alaska. Murrelet 48: 28-33.

Casey, A. E., B. K. Sandercock, and S. M. Wisely. 2011. Genetic parentage and local population structure in the socially monogamous Upland Sandpiper. The Condor 113: 119-128.

Chapman, R. N., D. M. Engle, R. E. Masters, and D. M. Leslie, Jr. 2004. Tree invasion constrains the influence of herbaceous structure in grassland bird habitats. Écoscience 11: 55-63.

Clark, R. G., and D. Shutler. 1999. Avian habitat selection: pattern from process in nest-site use by ducks. Ecology 80 : 272-287.

Clarke, K. R., and R. M. Warwick. 2001. Change in Marine Communities: An Approach to Statistical Analysis and Interpretation. Second edition. PRIMER-E Ltd, Plymouth, United Kingdom.

Clarke, K. R., and R. N. Gorley. 2006. PRIMER 6: User Manual/Tutorial. PRIMER-E Ltd, Plymouth, United Kingdom.

Coppedge, B. R., D. M. Engle, R. E. Masters, and M. S. Gregory. 2001. Avian response to landscape change in fragmented southern Great Plains grasslands. Ecological Applications 11: 47-59.

DeLong, A. K., J. A. Crawford, and D. C. DeLong, Jr. 1995. Relationships between vegetational structure and predation of artificial Sage Grouse nests. Journal of Wildlife Management 59: 88-92.

Dion, N., K. A. Hobson, and S. Larivière. 2000. Interactive effects of vegetation and predators on the success of natural and simulated nests of grassland songbirds. The Condor 102: 629-634.

Dwernychuk, L. W., and D. A. Boag. 1972. How vegetative cover protects duck nests from egg-eating birds. Journal of Wildlife Management 36: 955-958.
Garvey, M. E., E. Nol, D. W. Howerter, and L. M. Armstrong. 2013. A spatial analysis of factors affecting nesting success of shorebirds in the Canadian prairies. The Condor 115: 1-10.

Gochfeld, M. 1978. Incubation behaviour in common terns: influence of wind speed and direction on orientation of incubating adults. Animal Behaviour 26: 848-851.

Government of Canada. 2014. Climate data online. Government of Canada, Ottawa, Ontario, Canada. Accessed 8 March 2014. http://climate.weather.gc.ca/index e.html.

Grant, T. A., E. Madden, and G. B. Berkey. 2004. Tree and shrub invasion in northern mixed-grass prairie: implications for breeding grassland birds. Wildlife Society Bulletin 32: 807-818.

Grant, T. A., E. M. Madden, T. L. Shaffer, P. J. Pietz, G. B. Berkey, and N. J. Kadrmas. 2006. Nest survival of Clay-Colored and Vesper Sparrows in relation to woodland edge in mixed-grass prairies. Journal of Wildlife Management 70: 691-701.

Graves, B. M., A. D. Rodewald, and S. D. Hull. 2010 . Influence of woody vegetation on grassland birds within reclaimed surface mines. Wilson Journal of Ornithology 122: 646-654.

Houston, C. S., C. R. Jackson, and D. E. Bowen, Jr. 2011. Upland Sandpiper (Bartramia longicauda). In The Birds of North America Online. Edited by A. Poole. Cornell Lab of Ornithology, Ithaca, New York. Accessed 8 March 2014. http://bna.birds.cornell.edu/bna/species/580/.

Johnson, D. H. 1979. Estimating nest success: the Mayfield method and an alternative. The Auk 96: 651-661.

Johnson, R. G., and S. A. Temple. 1990. Nest predation and brood parasitism of tallgrass prairie birds. Journal of Wildlife Management 54: 106-111.

Jones, J. 2001. Habitat selection studies in avian ecology: a critical review. The Auk 118: 557-562.

Kirsch, L. M., and K. F. Higgins. 1976. Upland Sandpiper nesting and management in North Dakota. Wildlife Society Bulletin 4: 16-20.

Liebezeit, J. R., P. A. Smith, R. B. Lanctot, H. Schekkerman, I. Tulp, S. J. Kendall, D. M. Tracy, R. J. Rodrigues, H. Meltofte, J. A. Robinson, C. Gratto-Trevor, B. J. McCaffery, J. Morse, and S. W. Zack. 2007. Assessing the development of shorebird eggs using the flotation method: species-specific and generalized regression models. The Condor 109: 32-47.

Martin, T. E. 1993. Nest predation and nest sites: new perspectives on old patterns. BioScience 43: 523-532.

Mayfield, H. F. 1975. Suggestions for calculating nest success. Wilson Bulletin 87: 456-466.

McKinnon, L., P. A. Smith, E. Nol, J. L. Martin, F. I. Doyle, K. F. Abraham, H. G. Gilchrist, R. I. G. Morrison and J. Bêty. 2010. Lower predation risk for migratory birds at high latitudes. Science 327: 326-327.

Moen, J., K. Aune, L. Edenius, and A. Angerbjörn. 2004. Potential effects of climate change on treeline position in the Swedish mountains. Ecology and Society 9: 16.

Mong, T. W. 2005. Using radiotelemetry to determine range and resource requirements of Upland Sandpipers at an experimentally managed prairie landscape. M.S. thesis, Kansas State University, Manhattan, Kansas, USA.

Nouvet, S., W. Wilson, and K. Martin. 2008. Breeding records of the Surfbird, Wandering Tattler, American Golden-Plover, and Upland Sandpiper in the southwest Yukon Territory. Western Birds 39: 22-30. 
Powell, L. A. 2007. Approximating variance of demographic parameters using the delta method: a reference for avian biologists. The Condor 109: 949-954.

Proctor, E., E. Nol, D. Burke, and W. J. Crins. 2012. Responses of insect pollinators and understory plants to silviculture in northern hardwood forests. Biodiversity and Conservation 21: 1703-1740.

Rodrigues, R. 1994. Microhabitat variables influencing nestsite selection by tundra birds. Ecological Applications 4: $110-116$.

Smith, P. A., I. Tulp, H. Schekkerman, H. G. Gilchrist and M. R. Forbes. 2012. Shorebird incubation behaviour and its influence on the risk of nest predation. Animal Behaviour 84: 835-842.

Stokes, D. L., and P. D. Boersma. 1998. Nest-site characteristics and reproductive success in Magellanic Penguins (Spheniscus magellanicus). The Auk 115: 34-49.

Sturm, M., C. Racine, and K. Tape. 2001. Increasing shrub abundance in the Arctic. Nature 411: 546-547.
Szeicz, J. M., and G. M. MacDonald. 1995. Recent white spruce dynamics at the subarctic alpine treeline of northwestern Canada. Journal of Ecology 83: 873-885.

Turner, D. M. 2013. Habitat selection and life-history traits of breeding birds in the boreal-tundra ecotone, with special attention to the American Robin (Turdus migratorius). M.Sc. thesis, Trent University, Peterborough, Ontario, Canada.

Vickery, P. D., M. L. Hunter, Jr., and S. M. Melvin. 1994. Effects of habitat area on the distribution of grassland birds in Maine. Conservation Biology 8: 1087-1097.

Winter, M., D. H. Johnson, and J. Faaborg. 2000. Evidence for edge effects on multiple levels in tallgrass prairie. The Condor 102: 256-266.

With, K. A., and D. R. Webb. 1993. Microclimate of ground nests: the relative importance of radiative cover and wind breaks for three grassland species. The Condor 95: 401413.

Received 13 June 2013

Accepted 30 August 2013 